FOOD ANALYSIS

\title{
SQUARE-WAVE VOLTAMMETRIC METHOD FOR DETERMINATION OF FUMARIC AND MALEIC ACID-DETERMINATION OF FUMARIC ACID IN WINE
}

\author{
Rubin Gulaboski, ${ }^{1, *}$ Ilinka Spirevska, ${ }^{1}$ \\ Lidija Šoptrajanova, ${ }^{1}$ and Renata Slavevska ${ }^{2}$ \\ ${ }^{1}$ Institute of Chemistry, Faculty of Natural Sciences and \\ Mathematics, St. Kiril i Metodij University, P.O. Box 162, \\ Skopje, Republic of Macedonia \\ ${ }^{2}$ Faculty of Pharmacy, St. Kiril i Metodij University, \\ Skopje, Republic of Macedonia
}

\begin{abstract}
A square-wave voltammetric method for determination of fumaric and maleic acid is developed. Both acids undergo totally irreversible redox reaction in neutral and acid media. The square-wave voltammetric response of the investigated acids is sensitive to $\mathrm{pH}$, concentration of acids, type of the supporting electrolyte, as well as of the exciting signal parameters, such as frequency, amplitude and scan increment. All the experimental conditions as well as the instrumental parameters for quantitative determination of both acids
\end{abstract}

*Corresponding author. E-mail: rgulab@iunona.pmf.ukim.edu.mk

1719 
were optimized. The detection limits of $116 \mu \mathrm{g} / \mathrm{L}$ for fumaric acid, and $230 \mu \mathrm{g} / \mathrm{L}$ for maleic acid are estimated. The proposed method enables simultaneous determination of fumaric and maleic acid. The method is applied for determination of fumaric acid in 10 kinds of Macedonian wines.

Key Words: Square-wave voltammetry; Fumaric acid; Maleic acid; Wine

\section{INTRODUCTION}

The demand for detection of substances of environmental, clinical and forensic significance at a trace levels is growing tremendously. The electrochemical techniques, particularly the pulse voltammetric techniques, have appeared as a powerful and cheap tool in analytical chemistry. Among them, square-wave voltammetry (SWV) is the most advanced electroanalytical technique. It is well suited method for mechanistic study of the electrode reactions, as well as for quantitative determination of the electroactive species (1-6). The fast scan rate together with the large signal amplitude, as well as the ability to discriminate against the capacitate current, are some of the advantages of SWV, which make it a technique of choice developing a particular electroanalytical method (1-9). In our previous work we have applied this technique to develop a method for quantitative determination of aconitic acid (6).

In the present work we have investigated the voltammetric behavior of fumaric and maleic acid in order to develop an analytical method for their quantitative determination. Maleic and fumaric acid as polycarboxilic acids with one double bond are geometric isomers and hence exhibit different physical and physiological properties. Unlike the fumaric acid, which is often used as a foodstuff additive and as a row material for pharmaceutics, plasticizers, synthetic resins etc., the maleic acid is toxic, both to humans and animals, having a harmful effect on the respiratory system and urinary tract (10). It was recently found that fumaric acid has been used with some success to alleviate psoriasis symptoms (11). Several papers have been published on separation and determination procedures of fumaric and maleic acid utilizing the high-performance liquid chromatography (HPLC) in different type of samples such as wine, musts and vinegar (12-13).

Initial reports for the electrochemical properties of both acids at a DME can be found in the works of Elving et al. (14-15). Additional information about polarographic properties of both acids have been collected by 
Spirevska et al. (16-17). The presence of a double $\mathrm{C}=\mathrm{C}$ bond, conjugated with acid carbonyl groups makes the cis-trans isomers maleic and fumaric acids polarographically active compounds. The scheme for reduction of both acids can be represented as follows:

$$
\mathrm{HOOCHC}=\mathrm{CHCOOH}+2 \mathrm{e}^{-}+2 \mathrm{H}^{+} \rightarrow \mathrm{HOOCH}_{2} \mathrm{C}-\mathrm{CH}_{2} \mathrm{COOH}
$$

The authors mentioned above, have found that the polarographic responses of both acids are sensitive to $\mathrm{pH}$. Also, they observed one, two or three polarographic waves depending on $\mathrm{pH}$ of solutions as well as a shift of the half-wave potential of the acids in negative direction by increasing of the $\mathrm{pH}$.

The analysis of fumaric acid in wines is of considerable importance, because it allows the vivification process to be controlled. Due to the low concentration of fumaric acid in a variety of wine samples (ranges from 0 to $100 \mathrm{mg} / \mathrm{L})(12-13)$ a sensitive and low-cost analytical method for a routine analysis of wine samples is neccessary to be developed. For this purpose an attempt to develop a square-wave voltammetric method for quantitative determination of fumaric acid in wine has been made.

\section{EXPERIMENTAL}

All chemicals (fumaric acid, maleic acid, $\mathrm{KNO}_{3}$, citric acid, $\mathrm{NaH}_{2} \mathrm{PO}_{4}$, $\mathrm{HCl}$, borax and $\mathrm{NaCl}$, methanol, ethanol, obtained from MERCK) were reagent grade and used as received. The stock solutions of fumaric and maleic as well as all other solutions used for voltammetric measurements were prepared with twice distilled water. The general voltammetric behavior of fumaric acid has been investigated in a various supporting electrolytes with different $\mathrm{pH}$ values. The results for the peak potential $-E_{\mathrm{p}}$, peak current $-I_{\mathrm{p}}$, as well as half-peak width $-\Delta E_{\mathrm{p} / 2}$ of the $\mathrm{SW}$ responses are listed in the Table 1.

The voltammetric measurements were performed with a Princeton Applied Research Model 384B Polarographic Analyzer. A static mercury drop model $303 \mathrm{~A}$ with a surface area of $0.0149 \mathrm{~cm}^{2}$ was used as the working electrode. $\mathrm{An} \mathrm{Ag} / \mathrm{AgCl}$ (sat. $\mathrm{KCl}$ ) was the reference electrode and $\mathrm{Pt}$ wire was the counter electrode.

The solutions were degassed with high-purity nitrogen for 8 min prior to the measurements and for an additional $20 \mathrm{~s}$ before each scan. A nitrogen atmosphere was maintained throughout the experiments. Each scan was done on a separate mercury drop at room temperature. 
Table 1. The SW Voltammetric Response Parameters as a Function of the Supporting Electrolytes Tested for Fumaric Acid The Conditions Were: $c$ (fumaric acid) $=1 \times 10^{-4} \mathrm{~mol} / \mathrm{L}, f=120 \mathrm{~Hz}, E_{\mathrm{sw}}=20 \mathrm{mV}, \mathrm{d} E=4 \mathrm{mV}$

\begin{tabular}{|c|c|c|c|}
\hline Supporting Electrolyte & $I_{\mathrm{p}} / \mu \mathrm{A}$ & $E_{\mathrm{p}} / \mathrm{V}$ & $\Delta E_{\mathrm{p} / 2} / \mathrm{mV}$ \\
\hline $0.1 \mathrm{~mol} / \mathrm{L} \mathrm{HCl}$ & 1.620 & -0.76 & 110 \\
\hline $\begin{array}{l}0.1 \mathrm{~mol} / \mathrm{L} \mathrm{KNO}_{3} \\
\text { buffered to } \mathrm{pH}=2.8\end{array}$ & 1.840 & -0.964 & 100 \\
\hline $\begin{array}{l}0.1 \mathrm{~mol} / \mathrm{L} \mathrm{KNO}_{3} \\
\text { buffered to pH of } 3.5\end{array}$ & 1.820 & -0.996 & 104 \\
\hline $\begin{array}{l}0.1 \mathrm{~mol} / \mathrm{L} \mathrm{KNO}_{3} \\
\text { buffered to } \mathrm{pH} \text { of } 4.0\end{array}$ & 1.640 & -1.176 & 120 \\
\hline $\begin{array}{l}0.1 \mathrm{~mol} / \mathrm{L} \mathrm{KNO}_{3} \\
\text { buffered to } \mathrm{pH} \text { of } 6.2\end{array}$ & 1.800 & -1.500 & 100 \\
\hline $\begin{array}{r}0.1 \mathrm{~mol} / \mathrm{L} \text { borax } \\
\text { with } \mathrm{pH} \text { of } 8.6\end{array}$ & 1 & 1 & 1 \\
\hline
\end{tabular}

\section{Analytical procedure and sample preparation}

A $100 \mathrm{~mL}$ volume of each wine sample was subjected to digestion in order to reduce the sample volume to $10 \mathrm{~mL}$. Thereafter, the samples were filtered through a $0.45 \mu \mathrm{m}$ Milipore filter and passed throughout the $\mathrm{C}_{18}$ cartridge. $\mathrm{C}_{18}$ cartridge had previously been conditioned by means of successive washes with $10 \mathrm{~mL}$ of methanol and $10 \mathrm{~mL}$ of water followed by $10 \mathrm{~mL}$ of $10 \%$ ethanol. The eventual residues of fumaric acid were eluted with $2 \mathrm{~mL}$ of $10 \%$ ethanol. The fumaric acid was not retarded on the cartridge. This was confirmed by spectrophotometric measurement of fumaric acid in standard solution at $210 \mathrm{~nm}$, passed through the $\mathrm{C}_{18}$ cartridge. Final volume of about $10-12 \mathrm{~mL}$ was obtained. $100 \mu \mathrm{L}$ volume of the concentrate were placed in the voltammetric cell which contained $10 \mathrm{~mL}$ buffer solution and than SW voltammograms were recorded.

\section{RESULTS AND DISCUSSION}

\section{A. Fumaric Acid}

The SW voltammetric response of fumaric acid is mainly sensitive to $\mathrm{pH}$, concentration of fumaric acid, as well as of the exciting signal parameters (frequency $-f$, amplitude $-E_{\mathrm{sw}}$ and scan increment $-\mathrm{d} E$ ). 
A few square-wave voltammograms of $1 \times 10^{-4} \mathrm{~mol} / \mathrm{L}$ fumaric acid solution recorded in supporting electrolyte solutions with different $\mathrm{pH}$ values are presented in Figure 1. According to the properties of the voltammetric response, three different $\mathrm{pH}$ regions could be recognized. In the first region $(\mathrm{pH}<3.2)$ a single, well defined peak of fumaric acid (peak $\mathrm{I}$ in Figure 1) located at $E_{\mathrm{p}}=-0.880 \mathrm{~V}$ was observed. Within the second region $(3.5<\mathrm{pH}<5.5)$ the voltammetric response of fumaric acid is consisted of two SW peaks (see peaks I and II in Figure 2). Increasing pH of the medium caused both peaks to shift in negative direction. Within this region, the height of the peak I decreases gradually with increasing $\mathrm{pH}$, while the peak II continuously increases. However, the sum height of these two peaks observed in the second region is equal approximately with the peak height of the response observed at $\mathrm{pH}<3.2$.

The third $\mathrm{pH}$ region is characterized in supporting electrolytes with $\mathrm{pH}>6.0$, where only a single and well defined peak of fumaric acid was observed (peak III in Figure 1), located at potentials of about $E_{\mathrm{p}}=-1.60 \mathrm{~V}$. The height of the peak III is almost equal with the height of the SW peak I,

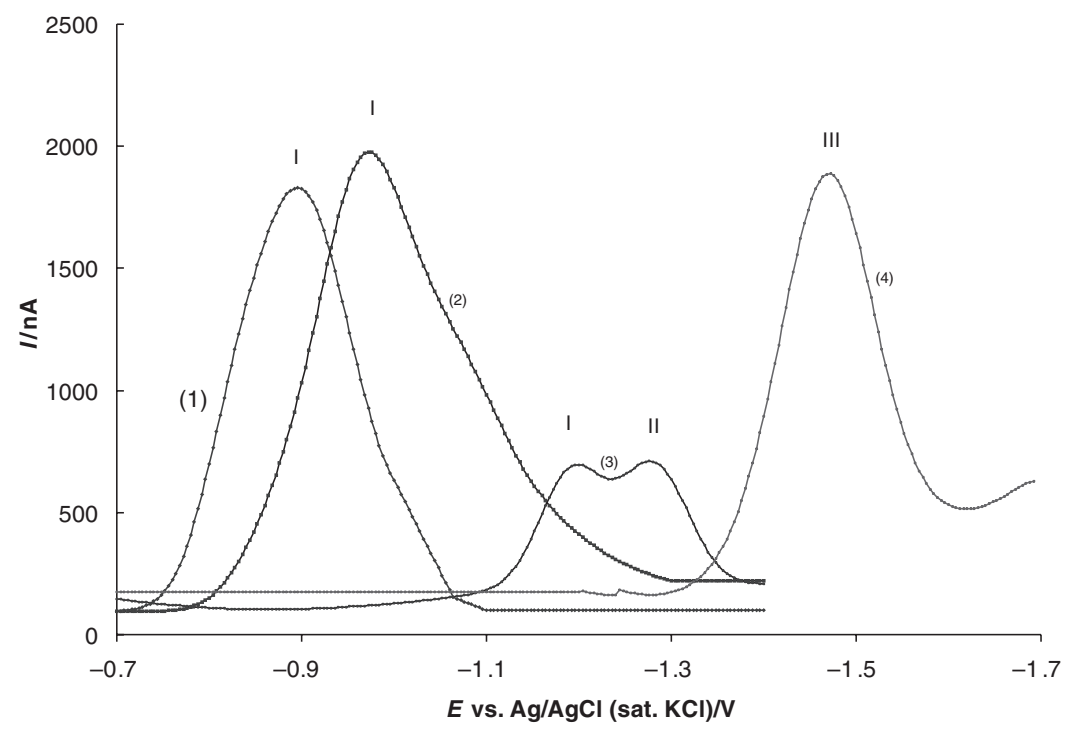

Figure 1. Square-wave voltammograms of fumaric acid recorded in $0.1 \mathrm{~mol} / \mathrm{L}$ $\mathrm{KNO}_{3}$ solutions buffered with $0.1 \mathrm{~mol} / \mathrm{L}$ buffer solution of citric acid and $\mathrm{NaH}_{2} \mathrm{PO}_{4}$ to $\mathrm{pH}$ of 2.8 (curve 1) 3.5 (curve 2), 5.0 (curve 3) and 6.2 (curve 4). The other conditions were: $c$ (fumaric acid) $=1 \times 10^{-4} \mathrm{~mol} / \mathrm{L}, f=120 \mathrm{~Hz}, E_{\mathrm{sw}}=20 \mathrm{mV}$, $\mathrm{d} E=4 \mathrm{mV}$. 


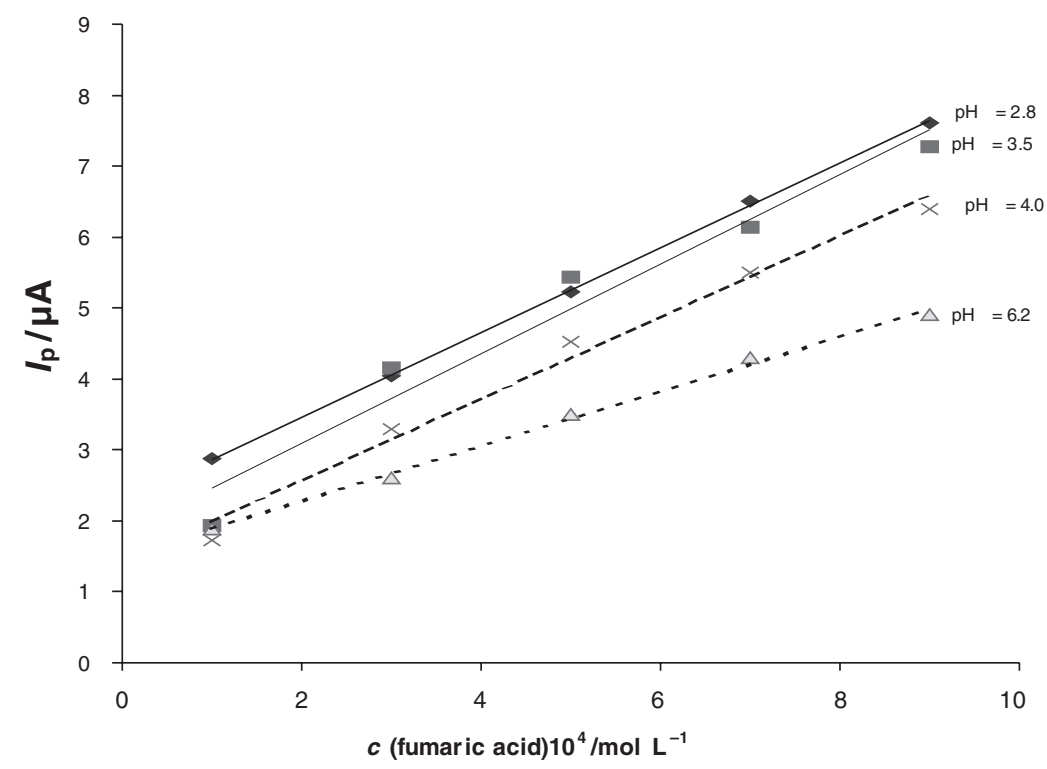

Figure 2. The calibration curves of fumaric acid recorded at different $\mathrm{pH}$ of the medium. The experimental conditions are the same as in Figure 1.

observed in the region with $\mathrm{pH}<3.2$. In the solution with $\mathrm{pH}>7$, the $\mathrm{SW}$ peak III commences decreasing intensively.

To give reasonable explanation for observed voltammetric behavior of fumaric acid at different $\mathrm{pH}$, one should carefully consider the acid-base equilibrium of this dicarboxylic acid, attributing with two dissociation constants $\left(\mathrm{p} K_{1}=3.45\right.$ and $\left.\mathrm{p} K_{2}=4.49\right)(18)$. Hence, depending on $\mathrm{pH}$ of the solutions, several different species of fumaric acid and different equilibria could exist. When $\mathrm{pH}<\mathrm{p} K_{1}$, only existing electroactive specie form in solution is undissociated form of fumaric acid $(\mathrm{HOOCHC}=\mathrm{CHCOOH})$. For this reason, only single SW peak arising from reduction of double $\mathrm{C}=\mathrm{C}$ bond of undissociated fumaric acid could be expected at $\mathrm{pH}<3.45$ (peak I).

In the region $\mathrm{p} K_{1}<\mathrm{pH}<\mathrm{p} K_{2}$, the following equilibrium in the fumaric acid solutions exists:

$$
\mathrm{HOOCHC}=\mathrm{CHCOOH} \leftrightharpoons \mathrm{HOOCHC}=\mathrm{CHCOO}^{-}+\mathrm{H}^{+}
$$

The existence of two electroactive species in the solution causes appearance of two voltammetric SW peaks. The first one (peak I) is attributed from the 
reduction of undissociated fumaric acid. The second SW peak (peak II) is attributed to the mono-dissociated anionic form of fumaric acid.

Finally, at $\mathrm{pH}>\mathrm{p} K_{2}$, the dianionic dissociated form of fumaric acid predominantly exists, gaing raise for appearance of a single SW peak located at most negative potentials (peak III).

As shown in Figure 2, the effect of fumaric acid concentration upon the SW peak current was studied in supporting electrolytes with different $\mathrm{pH}$ values. The slope of $I_{\mathrm{p}}$ vs. $c$ (fumaric acid) has the highest value in $0.1 \mathrm{~mol} / \mathrm{L}$ $\mathrm{KNO}_{3}$ solution buffered with $0.1 \mathrm{~mol} / \mathrm{L}$ buffer solution of citric acid and $\mathrm{NaH}_{2} \mathrm{PO}_{4}$ to $\mathrm{pH}$ of 2.8 , favoring this electrolyte as the most suitable for analytical purposes. So, further optimization of experimental conditions was carried out in this supporting electrolyte.

The SW frequency influences only to the peak current of the SW response of fumaric acid. The $I_{\mathrm{p}}$ is a linear function of the square root of SW frequency, indicating a diffusion-controlled electrode process. The max. ratio $I_{\mathrm{p}} / \Delta E_{\mathrm{p} / 2}$ was obtained at frequency of $120 \mathrm{~Hz}$.

The SW voltammetric response of fumaric acid was also sensitive to SW amplitude. Changing the SW amplitude from 10 to $50 \mathrm{mV}$ causes increasing of the peak current. At SW amplitude greater than $50 \mathrm{mV}$, the shape of the SW response significantly disturbed. It should be noted that the peak potential was not affected by the variation of the SW amplitude. An amplitude of $30 \mathrm{mV}$ was chosen as the most suitable for analytical purposes.

As a result of the optimization procedure, the following instrumental conditions were selected as optimal for quantitative determination of fumaric acid: frequency of $120 \mathrm{~Hz}$, amplitude of $30 \mathrm{mV}$ and scan increment of $4 \mathrm{mV}$. Calibration plots of fumaric acid were constructed over concentration ranges of $10^{-6}, 10^{-5}$ and $10^{-4} \mathrm{~mol} / \mathrm{L}$. The linear dependence between $I_{\mathrm{p}}$ and $c$ (fumaric acid) was observed, which are associated with following regression lines:

$$
\begin{aligned}
& I_{\mathrm{p}} / \mu \mathrm{A}=0.1338 c(\text { f.a. }) \times 10^{-6} / \mathrm{mol} \mathrm{L}^{-1}+0.308\left(\mathrm{R}^{2}=0.998\right), \\
& I_{\mathrm{p}} / \mu \mathrm{A}=1.007 c(\text { f.a. }) \times 10^{-5} / \mathrm{mol} \mathrm{L}^{-1}+0.871\left(\mathrm{R}^{2}=0.992\right), \text { and } \\
& \left.I_{\mathrm{p}} / \mu \mathrm{A}=5 c \text { (f.a. }\right) \times 10^{-4} / \mathrm{mol} \mathrm{L}^{-1}+4.88\left(\mathrm{R}^{2}=0.992\right),
\end{aligned}
$$

for $10^{-6}, 10^{-5}$ and $10^{-4} \mathrm{~mol} / \mathrm{L}$ concentration regions, respectively.

The detection limit (three times to noise) of $116 \mu \mathrm{g} / \mathrm{L}$ fumaric acid was estimated. The reproducibility of the method varied from 94.50 to $102.80 \%$ (eight measurements at $5 \times 10^{-6} \mathrm{~mol} / \mathrm{L}, 1 \times 10^{-5} \mathrm{~mol} / \mathrm{L}$ and $5 \times 10^{-5} \mathrm{~mol} / \mathrm{L}$ fumaric acid concentrations), followed with standard deviation of 0.45 to $3.20 \%$. 


\section{B. Maleic Acid}

The electrochemical behavior of maleic acid is quite similar to the behavior of fumaric acid. Figure 3 shows the voltammetric responses of $1 \times 10^{-4} \mathrm{~mol} / \mathrm{L}$ maleic acid solutions recorded in $0.1 \mathrm{~mol} / \mathrm{L} \mathrm{KNO}_{3}$ solutions as a supporting electrolyte buffered to different $\mathrm{pH}$ values with $0.1 \mathrm{~mol} / \mathrm{L}$ buffer solution of citric acid and $\mathrm{NaH}_{2} \mathrm{PO}_{4}$. A single reduction peak at potential of about $-0.85 \mathrm{~V}$ exists in solutions with $\mathrm{pH}$ up to 2.8 . Changing $\mathrm{pH}$ value from 3.0 to 5.6 two peaks of maleic acid were observed, separated each from other about $200 \mathrm{mV}$. At $\mathrm{pH}>5.6$ a single peak of maleic acid was observed again. The origin of these three SW peaks of maleic acid is quite identical as in the case of fumaric acid. The three distinct $\mathrm{pH}$ regions characterizing the voltammetric behavior of maleic acid are

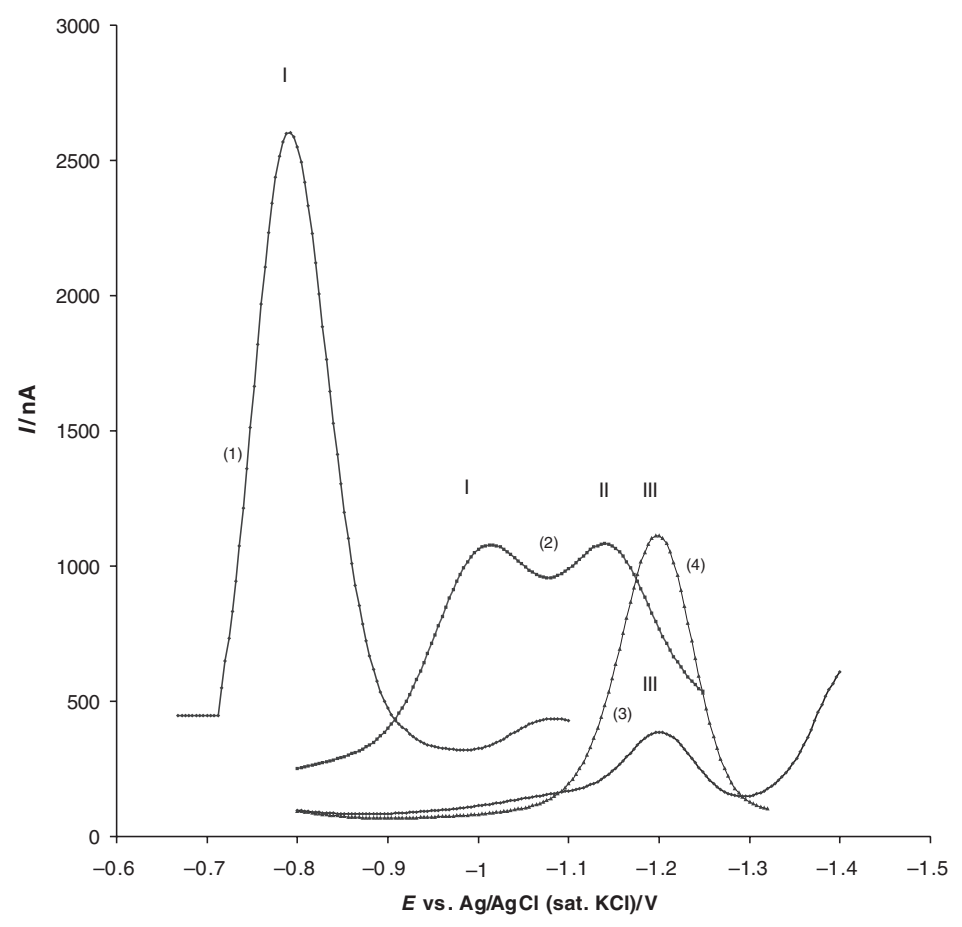

Figure 3. Square-wave voltammograms of maleic acid recorded in $0.1 \mathrm{~mol} / \mathrm{L} \mathrm{KNO}_{3}$ solutions buffered to $\mathrm{pH}$ of 2.5 (curve 1), 4.0 (curve 2), 5.6 (curve 3) and 6.0 (curve 4). The concentration of maleic acid was $c$ (maleic acid $)=1 \times 10^{-4} \mathrm{~mol} / \mathrm{L}$. The other conditions were: $f=120 \mathrm{~Hz}, E_{\mathrm{sw}}=20 \mathrm{~m}, \mathrm{~d} E=4 \mathrm{mV}$. 
determined by its dissociation constants which reads $\mathrm{p} K_{1}=1.83$ and $\mathrm{p} K_{2}=6.07$ (18).

The calibration plot constructed at $\mathrm{pH}$ of 1.8 (where single peak was observed) is more useful for quantitative determination of maleic acid as a single compound. Namely, the greatest slope of $I_{\mathrm{p}}$ vs. $c$ (maleic acid) in this case exists.

Generally the SW voltammetric response of maleic acid depends on the exciting signal parameters $\left(f, E_{\mathrm{sw}}, \mathrm{d} E\right)$ almost in same way as for fumaric acid. So, frequency of $120 \mathrm{~Hz}, \mathrm{SW}$ amplitude of $25 \mathrm{mV}$ and scan increment of $4 \mathrm{mV}$ were chosen as optimal for quantitative determination of maleic acid. The calibration curves were constructed over $10^{-6}, 10^{-5}$ and $10^{-4} \mathrm{~mol} / \mathrm{L}$ concentration ranges of maleic acid $\left(\mathrm{R}^{2}\right.$ greater than 0.998$)$, with the standard deviation of the results ranged from $0.5 \%$ to $4.8 \%$. The detection limit of $230 \mu \mathrm{g} / \mathrm{L}$ maleic acid was found.

\section{Mixture of Maleic and Fumaric Acid}

It is well known that even though voltammetric measurements may seem to involve the reactivity of individual elements or functional groups (the double $\mathrm{C}=\mathrm{C}$ bond in the case of fumaric and maleic acid), the effective peak potentials are due to the nature of the molecular environment adjacent to the functional group. Even the molecular environment adjacent to the functioning group is same, their geometric orientation in the space (e.g. cis and trans isomerism) also produce differences in the peak potentials.

The property of the electrochemical behavior of fumaric and maleic acid enables development of analytical procedure for simultaneous determination of both acids in mixture. Such a method would be of certain interest, since these acids often could be present in various samples. Utilizing the difference in the peak potentials of the SW voltammetric responses in solution with $\mathrm{pH}$ of about 3.5, a square-wave voltammetric method for simultaneous quantitative determination of both acids could be developed. Namely, using the derivative square-wave voltammetry is possible to separate both overlaped peaks and a method for simultaneous quantitative determination of both acids could be developed.

\section{Determination of Fumaric Acid in Some Wines from Macedonia}

The proposed electrochemical method for determination of fumaric acid was successfully applied to several types of Macedonian wines. At first, separation of fumaric acid from the complex matrix sample was 
neccessary. For this purpose, solid-phase extraction with $\mathrm{C}_{18}$ cartridge was applied. This method of separation is very convennient for the wine samples where predominanted compounds are nonpolar because they can be successfully retained on the cartridge. The details of the separation procedure are described in the part "Analytical procedure and sample preparation".

The concentration of fumaric acid in each extracted wine sample was determined by standard addition method in $0.1 \mathrm{~mol} / \mathrm{L} \mathrm{KNO}_{3}$ solution buffered to $\mathrm{pH}=2.8$ as a supporting electrolyte. Several voltammetric curves recorded after standard addition of fumaric acid are depicted in the Figure 4. It should be emphasized that four of each wine sample were analyzed. Also, four SW voltammograms were recorded for each probe, and the average peak current was calculated. Subsequently, several standard concentrations of fumaric acid were added in the cell and for each addition four square-wave voltammograms were recorded. The concentration of

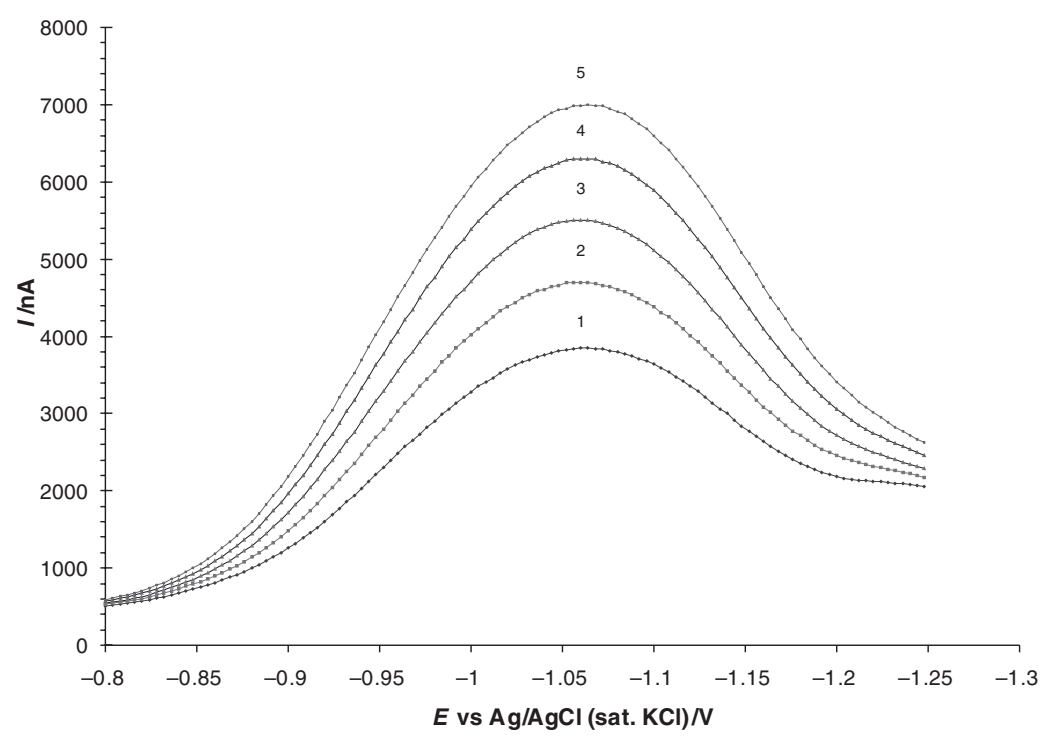

Figure 4. Standard addition SWV method for determination of fumaric acid applied to the "Smederevka" wine. The curve 1 is from sample wine without standard, and the curves 2, 3, 4 and 5 contains 2, 4, 6 and $8 \times 10^{-4} \mathrm{~mol} / \mathrm{L}$ standard solutions of fumaric acid, respectively. The experimental conditions were $E_{\mathrm{sw}}=30 \mathrm{mV}, f=120 \mathrm{mV}, \mathrm{d} E=4 \mathrm{mV}$, Supporitn electrolyte was $0.1 \mathrm{~mol} / \mathrm{L} \mathrm{KNO}_{3}$ solution buffered to $\mathrm{pH}=2.8$. 
Table 2. Contents of Fumaric Acid Determined by Square-Wave Voltammetry in Some Kind of Wines from Macedonia Supporting Electrolyte $0.1 \mathrm{~mol} / \mathrm{L} \mathrm{KNO}_{3}$ Buffered to $\mathrm{pH}=2.8$ Frequency $f=120 \mathrm{~Hz}$, amplitude $E_{\mathrm{sw}}=30 \mathrm{mV}$, Scan Increment $\mathrm{d} E=4 \mathrm{mV}$

\begin{tabular}{lcc}
\hline Kind of Wine & Y (fum.acid) $/ \mathrm{mg}^{-1}$ & St. deviation $/ \%$ \\
\hline Smederevka (from Tikves) & 20.05 & 2.33 \\
Alexandria & 22.25 & 3.45 \\
Belan & 17.20 & 2.45 \\
Temjanika & 30.35 & 1.35 \\
Country White & 16.75 & 0.50 \\
Chardonnay & 24.27 & 3.25 \\
ORO, Grenas Bel & 20.20 & 2.06 \\
Smederevka (from Veles) & 15.35 & 1.85 \\
Belo Velesko & 22.85 & 0.80 \\
Ohridija & 18.60 & 3.60 \\
\hline
\end{tabular}

*each data represents mean of the voltammetric measurements of four samples.

the fumaric acid in each wine sample was estimated according to the formula (19):

$$
Y=X+\left|\frac{Y_{o}-Y_{a}}{m}\right|,
$$

where $Y$ is unknown concentration of fumaric acid in wine sample, $X$ is a concentration of the standard added in the voltammetric cell, $Y_{o}$ is average peak current obtained from the wine sample, $Y_{a}$ is average peak current when standard of fumaric acid with concentration $X$ was added in the wine sample and $m$ is a slope of the linear regression line of the dependency $I_{\mathrm{p}}-c$ (standard of fumaric acid), obtained by the least squares method.

The results for concentration of fumaric acid obtained by this method in 10 kinds of wines from Macedonia are listed in Table 2. The concentration of fumaric acid in wine samples ranges from 15 to $30 \mathrm{mg} / \mathrm{L}$. The obtained results are in good agreement with the results presented in the literature (12-13).

\section{CONCLUSION}

In summary, square-wave voltammetry is a sensitive, rapid, precise and accurate technique for determination of fumaric and maleic acid, and 
by extension, of other unsaturated organic acids. This technique is also attractive due to the relatively low cost of the instrumentation and short time required for the analysis. The disadvantages of this approach are addressed to the determination in complex sample types (such a wine). Namely, the existing surface active compounds in the wine samples disable voltammetric determination of fumaric acid instantaneously from the wine. However, these disadvantages could be solved by means of separation techniques. The proposed method for quantitative determination of fumaric acid is a good alternative to other methods based on the HPLC determination (12-13). Proposed method is simple and rapid, enabling easy sample preparation, and hence it could be applied for routine analysis of fumaric acid in wine samples.

\section{REFERENCES}

1. Osteryoung, J.G.; Osteryoung, R.A. Square wave anodic stripping analysis in the presence od dysolved oxygen. Anal. Chem. 1985, 57 (1), 101A, 155 .

2. Ramaley, L.; Krause, M.S. Jr. Theory of square-wave voltammetry. Anal. Chem. 1969, 41 (11), 1362.

3. Stojanova, K.; Gulaboski, R.; Mirčeski, V.; Petrovska-Jovanović, S. Adsorptive stripping square-wave voltammetry of creatine. Anal. Lett. 1999, 32 (15), 2937.

4. Krause, M.S. Jr.; Ramaley, L. Analytical application of square-wave voltammetry. Anal. Chem. 1969, 41 (11), 1365.

5. Mirčeski, V.; Gulaboski, R.; Jordanoski, B.; Komorsky-Lovrić, Š. Square-wave voltammetry of 5-fluorouracil. J. Electroanal. Chem. 2000, 37, 490.

6. Spirevska, I.; Šoptrajanova, L.; Gulaboski, R. Square-wave voltammetric method for determination of aconitic acid. Anal. Lett. 2000, $33(5), 915$.

7. Osteryoung, J.; O'Dea, J.J. in Electroanalytical Chemistry, A.J. Bard Ed.; vol. 14, Marcel Dekker, Inc., New York, 1986, p. 209.

8. Brumleve, T.M.; Osteryoung, J.G. Theory of differential pulse voltammetry in the alternating pulse mode for totally irreversible electrode reactions. Anal. Chem. 1981, 53, 988.

9. Kounaves, S.P.; O’Dea, J.J.; Chandrasenkhar, P.; Osteryoung, J.G. Square-wave voltammetry at the mercury film electrode. Anal. Chem. 1986, 58 (14), 3199. 
10. Szczepaniak, W.; Ren, M. Determination of trace amounts of impurities in pharmaceutical preparations by differential pulse polarography. Anal. Chim. Acta 1993, 273, 3359.

11. Kolbach, D.N.; Nieboer, C. J. Am. Acad. Dermatol. 1992, 27, 769.

12. Tusseau, D.; Benoit, C. Routine high-performance liquid chromatographic determination of carboxylic acids in wines and champagne. Chrompsymp. 1987, 1097.

13. Romero, E.G.; Ibanez, M.D. Determination of organic acids in grape musts, wines and vinegars by high-performance liquid chromatography. J. Chromatogr. 1993, 655, 111.

14. Elving, P.J.; Rosenthal, I. Determination of maleic and fumaric acid in mixtures. Anal. Chem. 1954, 26, 1454.

15. Warhovsky, B.; Elving, P.J.; Mandel, J. Polarographic analysis of mixtures of maleic and fumaric acid. Anal. Chem. 1947, 19 (3), 161.

16. Spirevska, I.; Rekalić, V. Polarographic behavior of unsaturated acids in dioxane-water mixtures. Glas. Hem. Drus. Beograd 1984, 49 (2), 57.

17. Spirevska, I.; Rekalić, V. Polarographic behavior of cis and trans dicarboxylic acids in phosphate buffer. Glas. Hem. Drus. Beograd 1984, 49 (2), 45.

18. The Merck Index, An Encyclopedia of Chemicals, Drugs, and Biologicals, (Susan Budvari, Ed.) Merck \& Co., Inc., Rahway, N.J. USA, 1989.

19. Skoog, D.A.; West, D.M.; Holler, F.J. Analytical Chemistry, 7th edition, Saunders College Publishing, New York, 1996.

Received January 1, 2001

Accepted May 5, 2001 


\section{Request Permission or Order Reprints Instantly!}

Interested in copying and sharing this article? In most cases, U.S. Copyright Law requires that you get permission from the article's rightsholder before using copyrighted content.

All information and materials found in this article, including but not limited to text, trademarks, patents, logos, graphics and images (the "Materials"), are the copyrighted works and other forms of intellectual property of Marcel Dekker, Inc., or its licensors. All rights not expressly granted are reserved.

Get permission to lawfully reproduce and distribute the Materials or order reprints quickly and painlessly. Simply click on the "Request

Permission/Reprints Here" link below and follow the instructions. Visit the U.S. Copyright Office for information on Fair Use limitations of U.S. copyright law. Please refer to The Association of American Publishers' (AAP) website for guidelines on Fair Use in the Classroom.

The Materials are for your personal use only and cannot be reformatted, reposted, resold or distributed by electronic means or otherwise without permission from Marcel Dekker, Inc. Marcel Dekker, Inc. grants you the limited right to display the Materials only on your personal computer or personal wireless device, and to copy and download single copies of such Materials provided that any copyright, trademark or other notice appearing on such Materials is also retained by, displayed, copied or downloaded as part of the Materials and is not removed or obscured, and provided you do not edit, modify, alter or enhance the Materials. Please refer to our Website User Agreement for more details.

\section{Order now!}

Reprints of this article can also be ordered at http://www.dekker.com/servlet/product/DOI/101081AL100105355 